\title{
RESENHA
}

\section{ORGANIZAÇÕES AGROALIMENTARES ALTERNATIVAS}

\author{
Sociologie des systèmes alimentaires alternatifs. Une promesse de différence \\ Ronan Le Velly. Paris, France: Presses des Mines, Collection Sciences Sociales, 2017. 200 p.
}

Este livro aqui apresentado fez parte dos estudos de pós-doutorado que realizei ao longo dos anos de 2019 a 2020, sob a supervisão do Prof. Dr. John Wilkinson, no Programa de Pós-Graduação de Ciências Sociais em Desenvolvimento, Agricultura e Sociedade, da Universidade Federal Rural do Rio de Janeiro, com o objetivo de problematizar as práticas organizacionais de organizações que atuam em sistemas agroalimentares, especificamente em mercados “denominados alternativos". A problemática principal do livro é endereçada ao longo desta resenha, por meio de um dialógo interdisciplinar com o campo dos Estudos Organizacionais.

A produção e os novos modos de alimentação têm sido objetos de críticas contundentes a respeito dos resultados nefastos proporcionados pelas dietas alimentares contemporâneas, baseadas em carboidratos, proteínas animais e açúcares. Tais efeitos são resultantes majoritariamente da produção em massa de mercadorias simbolizadas pelo modelo 4 F Crops (Food, Feed, Fiber e Fuel) (Niederle \& Wesz, 2018), cujos atores principais são formados por conglomerados multinacionais que dominam as negociações de contratos nas bolsas mercantis na Chicago Board of Trade. Neste cenário contemporâneo complexo e dinâmico que afeta as organizações, as sociedades e os indivíduos, quais são as contribuições potenciais que o campo dos Estudos Organizacionais poderá oferecer para este debate, em diálogo com outros campos do conhecimento?

As controvérsias sobre 0 alimento nas sociedades modernas, os seus diferentes modos de produção e de consumo têm avançado para além do consagrado debate sobre as técnicas de produção agrícolas, os efeitos da Revolução Verde e o uso intensivo de novas tecnologias e insumos químicos na produção de alimentos.

Em livro recém-publicado na França sobre os sistemas alimentares alternativos, Ronan Le Velly afirma que, apesar da diversidade entre as organizações dos sistemas agroalimentares, é possível distinguir o mainstream do sistema agroalimentar em relação às organizações que compartilham o que o autor denomina como uma "uma promessa de diferença”. Essas organizações são detentoras de modos de produção particulares, que se difundem por práticas comerciais e de consumo denominadas como alternativas. Em outras palavras, estão atreladas a uma noção de "projeto" alternativo, com características bastante singulares entre si, resultando, com isso, na promessa de outras formas de organização dos sistemas agroalimentares, que são geradoras de benefícios para os indivíduos, para as sociedades e para o planeta.

As pesquisas empíricas sobre a alimentação, o consumo, os sistemas agroalimentares e os seus mercados vêm recebendo destacadas contribuições interdisciplinares, 
nas quais o campo dos Estudos Organizacionais tem participado de maneira incipiente, porém promissora. Com destaque, no Brasil, para o vol. 58, n. 3, maio-junho de 2018, da RAE, dedicado a uma edição especial para tratar do assunto. Mais especificamente em diálogos desse campo com a sociologia econômica, com a sociologia das organizações e com o pragmatismo. São diversos os fenômenos estudados por pesquisadores nacionais ou internacionais que se aproximam dos Estudos Organizacionais, com destaque para as pesquisas sobre os processos de inovação (organizacional e mercadológica), sobre os processos de mudança organizacional, ou, ainda, sobre a estruturação da ação coletiva, que ocorre dentro da esfera das organizações ou que emerge a partir dos mercados.

Como explicar, por exemplo, que os consumidores concordam em pagar mais por produtos orgânicos ou se engajam em trabalhos voluntários, impulsionados por valores e princípios que animam essas organizações? Tome como exemplo os casos emblemáticos do movimento internacional Slow Food ou da organização multinacional de comércio justo, Fair Trade International. 0 que faz com que os seus integrantes se mobilizem e se engajem em ações coletivas em defesa de um alimento, por exemplo, "bom, limpo e justo" (Slow Food, 2007)? Como são constituídas as formas que regulam as ações entre atores tão heterogêneos, que se mobilizam por um objetivo comum? Qual é o sentido em se falar em sistemas ou organizações agroalimentares alternativas quando as fronteiras dos sistemas convencionais e alternativos são tão imprecisas? O alternativo, nesses casos, é um atributo de distinção social para gerar valor econômico para as organizações empresariais ou deve ser compreendido a partir de outras lentes e características?

0 autor identifica dois eixos principais que estruturam a ação dessas organizações: as atividades de regulação de controle e as atividades de regulação autônomas. São essas atividades de regulação que, em última instância, as caracterizam e as diferenciam, além da noção de projeto que impulsiona as ações de seus atores.

Partindo da sociologia da ação organizada (Reynaud, 1988, 1997, 2003) em diálogo com a tradição clássica da Teoria Organizacional, as atividades de regulação de controle, típicas das organizações burocráticas (Crozier, 1963), são realizadas por grupos situados em posição hierarquicamente superior na estrutura organizacional, responsáveis por atividades que regulam e controlam o trabalho, ou que estabelecem padrões e processos que regulam as atividades organizacionais, como nos processos de compras de mercadorias, nas atividades de delegação do trabalho, no minucioso conjunto de regras escritas que compõe os padrões de qualidade reconhecidos comercialmente etc. Já as atividades de regulação autônomas referem-se às atividades realizadas por atores sujeitos ao controle e à pres- crição de suas atividades, e que buscam substituir as práticas dominantes por novos arranjos organizacionais.

A pluralidade de fontes de regulação torna difusa a determinação do locus de controle ou de autonomia da ação coletiva, pois estes não se encontram restritos aos domínios da organização, à sua estrutura organizativa, nem mesmo a um único grupo ou ator dominante. Mas disseminam-se por meio de redes de relações sociais e econômicas dentro ou fora da organização. As atividades de regulação incidem, nesse sentido, sobre as questões de cooperação e de coordenação entre os atores.

As atividades de regulação concorrem para a estruturação da ação coletiva, que é constituída por coletivos híbridos: atores, relacionamentos, ações, regras, dispositivos materiais, rotinas, discursos etc. Essas atividades estabilizam-se provisoriamente nas relações sociais das organizações, nos acordos, decisões e práticas organizacionais vigentes e aceitas. 0 vínculo entre os atores e a ação coletiva, derivada das atividades de regulação, resulta na formação de coletivos organizacionais, tais como uma empresa, uma cooperativa ou um movimento social.

Essas noções estão presentes na teoria ator-rede, de Akrich, Callon e Latour (1988), na sociologia dos agenciamentos mercantis de Michel Callon (1998, 2013), assim como nos conceitos de mediação mercantil (Latour, 2006). Todas essas abordagens têm sido utilizadas de modo crescente nos Estudos Organizacionais, em temas diversos, que não se restringem ao sistema agroalimentar.

A partir deste ponto, Le Velly destaca que os espaços de indeterminação da ação coletiva resultam em zonas de incerteza, possibilitando a abertura de novos espaços de negociação das regras estabelecidas. Tais espaços representam as “margens de manobra” dos atores (Crozier, 1963; Crozier \& Friedberg, 1977), pois “as normas são sempre incompletas e ambíguas, passíveis de serem interpretadas" (Velly, 2017, p. 29). A capacidade estratégica dos atores em "descobrir e experimentar novos recursos e novas maneiras de jogar o jogo" sinaliza, do ponto de vista mercantil, a oportunidade de inovação na busca pela ampliação do controle e aumento do poder sobre as regulações de mercado, seja por meio da introdução de novos produtos, novas práticas, processos organizacionais ou pela criação de novos nichos de mercado. Tais inovações estratégicas, assim como a implementação de dispositivos como a "marca, a embalagem ou o crédito ao consumidor” (Velly, 2017, p. 29), são exemplos concretos resultantes do processo de embate entre os grupos, subjacentes às atividades de regulação de mercado.

0 livro nos fornece caminhos para responder a algumas das perguntas levantadas nesta resenha, ao propor um quadro teórico bastante original, que dialoga diretamente com a Teoria Organizacional, com o objetivo de guiar empiricamente os estu- 
dos de casos franceses, que o autor vem investigando desde o início dos anos 2000.

São apresentados três estudos de caso sobre as cadeias locais de abastecimento alimentar, que evidenciam os processos de geração da alternatividade com foco nos processos de hibridização desses sistemas. São identificadas as atividades de regulação operadas para atender o abastecimento alimentar de alimentos orgânicos, conformadas por meio de restrições e condicionantes impostas pelo arcabouço legal de compras ou por práticas dominantes de empresas que atuam principalmente em circuitos longos. Em ambas as situações, são abertos espaços e oportunidades para a inovação mercantil e a reconfiguração do fenômeno estudado.

Os últimos dois capítulos discutem os efeitos gerados pelo crescimento da escala comercial de duas destacadas iniciativas. O caso apresentado reconstitui o processo de convencio-

\section{REFERÊNCIAS}

Akrich, M., Callon, M., \& Latour, B. (1988). À quoi tient le succès des innovations? 1: L'art de

l'intéressement; 2: Le choix des porte-parole. Gérer et comprendre. Annales des mines, $1(11 \& 12), 4-17$ \& 14-29. Recuperado de https:// halshs.archives-ouvertes.fr/file/index/docid/81741/filename/SuccesInnovation.pdf

Boltanski, L., \& Thévenot, L. (1991). De la justification: Les économies de la grandeur. Paris, France: Gallimard.

Callon, M. (1998). Introduction: The embeddedness of economic markets in economics. The Sociological Review, 46(S1), 1-57. doi: 10.1111/j.1467-954X.1998.tbo3468.X

Callon, M. (2013). Qu'est-ce qu'un agencement marchant? In M. Callon, M. Akrich, S. Dubuisson-Quellier, C. Grandclément, A. Hennion, B. Latour, ... V. Rabeharisoa (Dir.), Sociologie des agencements marchands: Textes choisis (pp. 325-440). Paris, France: Presses des Mines.

Crozier, M. (1963). Le phénomène bureaucratique, Paris, France: Seuil.

Crozier, M., \& Friedberg, E. (1977). L'acteur et le système: Les contraintes de l'action collective. Paris, France: Editions du Seuil.

Friedberg, E. (1993). Le pouvoir et la règle: Dynamiques de l'action organisée. Paris, France: Editions du Seuil. nalização da iniciativa Fairtrade, fenômeno denominado pelo autor como o mainstreaming do comércio justo, por meio das organizações Max Havelaar na França e Holanda, e Fairtrade International. Le Velly não se restringe a compreendê-las somente pelos arcabouços teóricos da economia das convenções (Boltanski \& Thévenot, 1991) ou das cadeias de valor globais (Gereffi \& Sturgeon, 2005), mas, sobretudo, pela mobilização de aportes recentes da nova sociologia econômica em diálogo com a Teoria Organizacional.

Em síntese, o livro aporta contribuições relevantes e inéditas para estudantes brasileiros de pós-graduação e pesquisadoras/es interessadas/os no tema das organizações e dos sistemas agroalimentares, assim como promove um diálogo profícuo com os Estudos Organizacionais, aproximando esse campo do conhecimento da sociologia econômica.

Gereffi, G. H. J., \& Sturgeon, T. (2005). The governance of global value chains. Review of International Political Economy, 12(1), 78-104. doi: 10.1080/09692290500049805

Latour, B. (2006). Changer de société, refaire de la sociologie. Paris, France: La Découverte.

Niederle, P. A., \& Wesz, V., Jr. (2018). As novas ordens alimentares. Porto Alegre, RS: Ed. UFRGS.

Reynaud, J. D. (1988), Les régulations dans les organisations: régulation de contrôle et régulation autonome. Revue française de sociologie, 29(1), 5-18. Recuperado de https://www.persee.fr/doc/ rfsoc_0035-2969_1988_num_29_1_2475

Reynaud, J. D. (1997). Les règles du jeu: L'action collective et la régulation sociale. Paris, France: Armand Colin.

Reynaud, J. D. (2003). Régulation de contrôle, régulation autonome et régulation conjointe. In Terssac de, G. (dir.), La théorie de la régulation sociale de Jean-Daniel Reynaud. Débats et prolongements, Paris, La découverte, 3-36.

Slow Food. (2007). Manifesto Slow Food. Recuperado de http://www. slowfoodbrasil.com/slowfood/filosofia.

Velly, R. L. (2017). Sociologie des systèmes alimentaires alternatifs. Une promesse de différence. Paris, France: Presses des Mines.

\section{CONTRIBUIÇÃO DO AUTOR}

Renê Birochi trabalhou na conceitualização e abordagem teórica-metodológica, na revisão teórica e redação e revisão final do manuscrito 